\title{
Music and Cephalic Capability
}

Pragmatist's Insights

Jay Schulkin

\section{(2) OpenEdition \\ Journals}

Electronic version

URL: http://journals.openedition.org/ejpap/2299

DOI: 10.4000/ejpap.2299

ISSN: 2036-4091

Publisher

Associazione Pragma

Electronic reference

Jay Schulkin, "Music and Cephalic Capability", European Journal of Pragmatism and American Philosophy [Online], XIII-1 | 2021, Online since 02 April 2021, connection on 04 April 2021. URL: http://

journals.openedition.org/ejpap/2299 ; DOI: https://doi.org/10.4000/ejpap.2299

This text was automatically generated on 4 April 2021.

\section{(c) $(1) \&$}

Author retains copyright and grants the European Journal of Pragmatism and American Philosophy right of first publication with the work simultaneously licensed under a Creative Commons AttributionNonCommercial-NoDerivatives 4.0 International License. 


\title{
Music and Cephalic Capability
}

\author{
Pragmatist's Insights
}

\author{
Jay Schulkin
}

\section{Introduction}

1 John Dewey, in his book Art as Experience, stated directly, "Because experience is the fulfillment of an organism in its struggles and achievements in a world of things, it is art in germ. Even in its rudimentary forms, it contains the promise of that delightful perception which is aesthetic experience." (Dewey 1934/1958: 19). Aesthetics, as Dewey so well understood, was part of the experience of inquiry; art as experience was not separate or for the parlor but endemic to inquiry: "aesthetic cannot be sharply marked off from the intellectual experience" (ibid.: 38). It was essential for the reconstructive of aesthetics to the knowing process and the expansion of human experience and human knowledge. Aesthetic features are at the heart of the contours of basic experience, something that speaks to our evolutionary history.

2 Creative expression, such as music, arises from core capabilities, generative processes, to combine with increasing ecological/cultural opportunities. Like everything else about us, with expanding environments, there is a greater diversity of expression. We explore the world to discern what we need, what is valuable (Dewey 1939), what we can build and construct, and forging of essential social links.

3 I use the term "cephalic" (e.g., Schulkin 2000; 2004) to include both brain/bodily/mind and transactions with objects and others. This is consistent with the classical pragmatist tradition, particularly that of John Dewey. And it was Dewey that quite gracefully embraced naturalism without reductionism, amid a sense of our cultural evolution, in which aesthetics is quite pervasive.

4 In what follows, first, I place aesthetics and music in this context of our natural transactions with each other and part of our evolutionary history. Second, I highlight that musical aesthetics is shared, social and rich with movement and meaning. Third, I argue that musical transactions are replete with expectations, codified by predictive coherence, inference and conservation, a natural melody across the continued 
orchestration of appetitive and consummatory experiences. Thus, I begin with a discussion of a pragmatist view of lively adaptation, followed by diverse ways in which adaptive systems underlie musical sensibility and human meaning. I then turn to the important link between expectations in music, probability, inference or abduction and brain activation. Finally, I end with a brief discussion of music and human well-being.

\section{Lively Adaptation: A Pragmatist View}

5 Aesthetics is the oxygen that enlivens experience, underlies our expectations. Objects for us are always, in some sense, social objects, and our adaptive cephalic systems are expanded in use in social contexts. Underlying the behavior of what we might call a basic proclivity to sing and to express music are appetitive urges, consummatory expression, drive and satisfaction. Appetitive expression is the buildup of need, and consummatory experiences are its release and reward. Musical appetitive and consummatory experiences are embedded in culturally rich symbols of meaning.

Dewey (1910) early on noted that the impact of Darwin on philosophy should be profound. And it has been. For pragmatists like Dewey critical realism and naturalism grounded in object knowledge and linked to habits, active inference, and grounded in good enough problem solving or reason were further placed in a biological context. He would suggest that with regard to the mind and adaptation, key questions are rooted in terms of change and function, context and resolution. Aesthetics is just part of these events, common events in our experiences.

7 Dewey (1895) like Darwin (e.g., 1872) highlighted the adaptive significance of many of our emotions. And importantly neither separated emotion and cognition. Darwin, and certainly John Dewey, understood that emotions are rich in appraisal processes. Pragmatists like Dewey noted that there are diverse forms of appraisals or valuation (Dewey 1939, 1966) many of which are affectively rich (e.g., Colombetti 2017). What the pragmatists emphasize, is engagement with the world, dilution of diverse dualism (e.g., mind/body, cognition/affect, fact/value) information transfer and communicative interaction with others in lively adaptive engagements.

While musical expressions are not simply about adaptation, there is rich affectively laden information essential for lively experiences of value. In other words, music is rich in information processing. Nothing is detached and the cognitive resources are rich in the generative processes within the expectations that surround music. The ecological context minimizes the neural/cognitive expenditures or can expand them as the living subject is in the "transactions" with others (Dewey 1925; Schulkin 2011; Engel, Friston \& Kragic 2015). The resources are linked to the ecological/social milieu, to what is available, what is dependable, what is utilizable, as well as the ability to use and unload information into environments that expand, enable, and bolster memory function as core cognitive events (Gibson 1979; Donald 2004; Clarke 2008).

Art, like science, is embedded in discovery, test, experiment, and expansion through technique. There is no divide between the scientific and the artistic. They run into each other quite readily and naturally as they expand the human experience. Moreover, music evolved from communicative functions into a highly cognitive action, a piece of aesthetics that happens to occur - and we, of course, are all the better for it. 

ecological exposure to and expectations about sound and meaning, music, and context, pervading our musical sensibilities (Clarke 2008). It is this sense of grounding that makes features stand out so easily in music and enables the mutualism between the perception, action, and external events that are quite palpable in music (Clarke \& Cook 2004). Events are always relative to a framework of understanding; a social context rich in practice, style, and history.

11 The expansion of memory facilitates the wide array of what we do (Donald 2001, 2004; Clark 1998), including music. The emphasis is on action and perception knotted together and coupled to events - in this case musical events, listening to and participating in them. Memory and action rich in perception crosses the entire realm of musical expression. The events are inherently anticipatory (Dewey 1896; Friston 2010). The search for and sustaining of order is a core feature of an active nervous system (Sterling \& Laughlin 2017); our expectations and habits are replete with them in the organization of action and our continued viability. Anticipatory systems fill in gaps (Loewenstein 1996; Berlyne 1970), as expectations run rampant across the nervous systems. So too with music (Koelsch, Vuust \& Friston 2018).

Action sequences are well orchestrated and embedded in successful survival for both short and longer-term expression; they are embedded in diverse forms of enaction with tasks, musical or otherwise. Importantly, biologically derived cognitive systems are not divorced from action or perception, but are endemic to them; running through experience and action are the practices that pervade human experience as are the expectations that bind us together and that organize our life (Dewey 1896; Berthoz 2002; Schulkin 2000).

13 Music is the kind of thing that is an action but which can also permeate our imagination, whether it is heard by someone, or simply imprints ruminants in cephalic systems. To paraphrase, music plays inside our heads, and as we shall see, common neural circuits underlie the action of both playing and hearing music, as well as imagining the music in reverberation (Jeannerod 1997). The cognitive/affective unconscious is essential for adaptation to a changing landscape and for aesthetic sensibility (Helmholtz 1873; Rozin 1976).

\section{Movement and Meaning}

We bring with us diverse forms of cephalic capabilities that underlie what Dewey used to call "lived experiences" or what others have called "embodied cognition" (Varela, Rosch \& Thompson 1991; Lakoff \& Johnson 1999). And these experiences are rich meaning, and movement in part by aesthetic sensibility.

15 Music is often full of purpose and bound to movement, whether literal or not (Zbikowski 2005). This goes from the structured ballet of Chopin-type music, with its endless practice and the expansion of musical movements, through Charles Ives's "The Fourth of July." Music is expanded to meaning, stories and living experience running together in both long and short sentences.

16 Our sense of self and our sense of music are often rooted in our life histories or our trajectory of movement through space. The emphasis is on embodied and expanded cephalic capability.

European Journal of Pragmatism and American Philosophy, XIII-1 | 2021 
17 Dewey endlessly wrote about the diverse forms of action; action is a key category in his philosophical arsenal; motion and movement towards goals. The sense of motion and movement is a fundamental feature in most forms of musical experience, within which emotion is tied to movement (Bachorik et al. 2009). The appraisal of movement and tempo are expectations of the music, locked together into coherence, and are a fundamental feature in the coherence of perception and action; action and perception (Gallese et al. 1996; see also Kruse 2005, 2011).

Bodily sensibility is running through music (Langer 1953; Johnson 2007; Schulkin 2004). Music is tied to movement and memory with vivid imagery, such as the one cited as "over the rainbow" and the expansion of our horizons by metaphors, as in George Harrison's "something in the way she moves me" (Johnson \& Larson 2003). The metaphors of movement and destination traverse the "musical landscape."

19 The complicated and endlessly intricate movements of the dances of India are infused throughout with religious sensibility. These expanding categories of understanding, always towards the mystical and endless transcendental sensibility, are usually based on a narrative of travel, of being on a path. Human life is always rich in terms of ends in view and transactions and transitions.

20 An inherent tension in aesthetic sensibility, particularly in music, is the search for stability amid change, interest, and exploration (Dewey 1934). The construction of events shapes the way we orchestrate action in music and otherwise. The shared experience with one another is a fundamental adaptation (Tomasello \& Carpenter 2007), and the innervations of bodily sensibility are a pervasive common element in our evolution (Damasio 1994; Schulkin 2004; Berthoz 2002). Pragmatists are not prone to commit "Descartes' Error." Bodily sensibility is inherent in living systems probing for predictive coherence (Gallagher 2005, 2020; Schulkin 2004).

21 Our sense of moving through musical space or projecting ahead is influenced by experience and language. Of course, within this sense lies the effort of reading the minds of others, mirroring others, attributing intentional acts, and cooperating or not, all of which are features of music as a social medium of the human condition (Cross 2009; Miell, MacDonald \& Hargreaves 2005).

22 Perhaps not surprisingly, our sense of motion, movement, and physical sensibility impacts our sense of time and space. This means that there is a bodily component to our sense of time and memory of events, which is rich in sensorimotor experiences, as well as agency and action - and the experiences of music are boundless with their sense of movement. As Erich Clarke notes, "Musical sound requires and inevitably involves movement" (Clarke 2008: 63).

Consider the pointing of the conductor bringing together the diverse instruments and people in an orchestra, pointing to quiet or accentuate, integrate, exaggerate to facilitate the melodic tapestry of harmonic and disharmonic moments; inherent in the conductor's pointing is a plethora of cognitive systems linking with others by simply pointing (Tallis 2010; Hatten 2004). Each of the gestures made by the conductor is unique (e.g., pointing). And so, gestures are also unique and multi-faceted, like speech.

24 Now consider the bass player. Watch the bass player "making love" to the bass, the physicality of the clarinet and saxophone players, the drummer, the song and melody reflecting the pervasive presence of gesture in musical sensibility. It is the body, as Merleau-Ponty systematically pointed out (1962) with gestures, "haunting" the space of 
interaction that is richly expressed within the landscape of human action, human meaning, and human social exchange. Cortical expansion (Dunbar 2016), diverse informational molecules contributing to the organization of action, and social contact (e.g., dopamine, Berridge 2004, neuropeptides, endorphins, oxytocin, Tarr, Launay \& Dunbar 2014; Schulkin 2011) are fundamental to this capability (Dunbar 2016), as well as diverse forms of cooperative or non-cooperative behaviors (Tomasello 2009; Reader \& Laland 2002).

\section{Musical Expectations}

John Dewey, in his book The Quest for Certainty, demythologized human knowing. Dewey posited that the real world of doing and knowing is within a codification of uncertainty. We seek to secure the stable and hold it while we grapple with the endless uncertainty. We make our peace with the uncertain as we forage within inquiry and infuse our transactions and transitions with objects, with each other, by foraging for predictive coherence- a critical feature of pragmatism (see Schulkin 2004; Williams 2018).

Grappling with uncertainty is a commonplace occurrence across diverse species. Pragmatist musicologists, like Leonard Meyer, understood that uncertainty is a basic fact of our existence; and that cognitive architecture and social context are continuous and rooted in determining relevant information. Music is lodged within the familiar to us and amid horizons of the less familiar as we explore new domains. Meyer understood and used the term "embodied meaning" for musical experiences with regard to the transactions of human beings in the context of musical meaning in our lives (Meyer 1956, 2000).

of course, in some contexts the repetition of the familiar is part of the experience of music. Indonesian gamelan bands depend on the repetition of an already-familiar musical motif with minor tone variations in some form of endless. But variation at many levels of appraisal, however, is a feature of most musical experience. Both Mozart and Coltrane delighted in slight deviations in expectations and musical sensibilities pervading the familiar. John Coltrane's recording of the song "Some of My Favorite Things," written by Oscar Hammerstein and Richard Rodgers for "The Sound of Music," relies on the familiarity of the audience with the song to launch into magnificent variations, expected and unexpected, as he expanded into novel uncharted territory.

The play of ideas amidst the uncertainty of one's existential condition defines an aesthetics in which probability expectations are part of our everyday cognitive adaptation, in music or otherwise. The codification of well-worn habits and expectations is the grounding frame in which musical orientation takes place; it requires well-orchestrated habits, cognitively mediated in regions of the brain that underlie repetitive occurrences and their breakdown. Dewey suggests that "[ $t]$ he road from a perceptible experience which is blind, obscure and fragmentary, meager in meaning, to objects of sense which are also objects which satisfy, reward and feed intelligence is through ideas that are experimental and operative" (Dewey 1929: 168).

For pragmatists anchored to biology, such as Meyer, pragmatism is knotted to aesthetic experiences inherent in everyday life and in shared experiences. In this view, expectations are pervasive within the organization of action, musical or otherwise (Dewey 1934). 

proximity to the direction of the music. He ties this organizational sensibility to "heuristic listening." Scale tones set up diverse expectations amidst surprises and "sweet anticipation." Indeed, "some surprises start right from the moment a work begins. When Igor Stravinsky began his 'Rite of Spring' with a solo bassoon, he violated several well-known conventions in classical music. The vast majority of Western orchestral works do not begin with a solo. Moreover, the bassoon is one of the least likely orchestral instruments to perform by itself. Finally, Stravinsky placed the instrument at the very top of its range. In other words, Stravinsky began the 'Rite of Spring' in a highly unorthodox (that is, improbable) way" (Huron 2008: 270). That shock of unexpectedness mimics the way the season of spring itself surprises us after the cold of winter.

Exptations and variations are common themes for which musical structure sets the conditions for diverse musical expression. We create the same sort of variation on themes by naming places in unfamiliar regions after familiar ones as we explore the new (New Amsterdam and New York, for instance as names for the settlements on Manhattan, first by the Dutch and then by the English), as well as by exploring new food sources while accompanying them with familiar condiments (Rozin 1998). (Think of the way children can be introduced to news foods by the addition of something familiar, like ketchup.) In music, we similarly explore the unfamiliar; perhaps it is another way in which we attempt to placate unease, uncertainty.

Surprise and tension underlie most of human experience, but it takes new and extraordinary forms in music. Indeed, such events pervade the sense of musical experience (Narmour 1990; Gjerdingen 1990; Russo \& Cuddy 1999; Cuddy \& Lunney 2005). Consider, for instance, the expectations we have concerning melodic intervals (Thompson, Cuddy \& Plaus 1997). Cephalic capabilities underlie diverse forms of human expression, and predictability is a core feature of the brain's responses to rhythmic expectations (Vuust et al. 2009; Morgan et al. 2019). The sense of musical expectation is embedded in appraisal systems, replete with emotions.

Since uncertainty is a basic feature of our existence, we have evolved a wide variety of resources to cope with it. Moreover, as Meyer has noted, "[...] uncertainty is anathema to humankind" and "we devise ways of reducing uncertainty both in the out-there world and in our personal lives [...]" but "[...] in the arts and other playful activities such as sports, games and gambling we actually relish and cultivate a considerable amount of uncertainty" (Meyer 1967: 261; Huron 2008; see also Krumhansl 2002; Sloboda 2008).

So, while we eschew uncertainty in our daily lives, we are also emotionally involved with, and "play" with, its reverberations in music and other aesthetic expressions. Probability and detection of discrepancies are a definitive part of problem solving and are also one part of aesthetic judgment. Many issues related to probability have been couched in terms of expectations. Indeed, syntactic predictions may have their basis in general issues about probability and human reasoning.

The sense of change is what underlies the appreciation of knowledge, music, and adaptation; the sense of uncertainty is part of the interplay of the regularity of the expected with a deviation, however slight, that keeps our interest. Such is the structure of musical expectation, amid style and form; staying the same, alternatively, is surely not a feature of many musical forms, although variation within set parameters is a

European Journal of Pragmatism and American Philosophy, XIII-1 | 2021 
recurrent musical feature. A broad-based response to discrepancy is an important behavioral adaptation, underlying aesthetic sensibility; curiosity can be pleasurable. A sense of pleasure in music is related nuanced novelty, even of the familiar (Berylne 1970). One hears something new in the music.

We forage for social coherence by relying on the familiar amidst the unfamiliar, and it is this relationship that permeates much of our experience in music, and indeed in most avenues of human expression (Schulkin 2011). Meyer understood that melodies are often acting on more than one level, in which there is the familiar and the unexpected. We are anchored to frames of reference in which there are expectations, detection of deviations or gaps, and then exploration. Continuity, building on the insights of C.S. Peirce (Peirce 1868, 1898), is a primary feature of expectations situated in a cultural and contextual milieu, within a "cultural style" (Meyer 1956, 1967).

Expectations are a core feature of cephalic organization. Repetition is essential in habit formation (Peirce 1898; Dewey 1929) and small deviations underlie responses to even the smallest novelties. These factors operate in music as well as in daily life (Narmour 1990; Rozin \& Rozin 2006) Expectations underlie a pattern itself, and are indeed part of the pattern. A common pattern in Western music (and also Western humor) is the repetition of two similar phrases followed by a dissimilar event, the A-B-A-B-C pattern (Rozin \& Rozin 2006). So, a break in expectation is perhaps part of sustaining coherence (Narmour 2008).

Of course, the tension in a piece linked to expectation and variation from expectation is an underlying factor; tension and release, build up and reduction, are core features of musical aesthetics - interactions of affective tone to emotional expression (Dewey 1896; Meyer 1956; Lerdahl \& Jackendoff 1983; Krumhansl 2002). For instance, melodic expectations are a continuum in our musical sensibility, and also appear to be tied to information processing, the sound of music (the tension and release).

Statistics are embedded in practices in which projectability of more entrenched reliability and predictive patterns are depended upon (Goodman 1955/1978) and noticed when they break down. This view underlies reasoning about musical expectation, and to some extent about art more generally, in which a mixture of expectation and discrepancy is held to underlie the aesthetic sensibility (Dewey 1934). The mental tools used in statistical reasoning also underlie diverse forms of musical competence, replete within a social context of playing with others. They permeate the cogitative processes involved in listening to music and motivate our response to violations of musical rules (Meyer 1956; Huron 2008; Smith \& Melara 1990; Juslin \& Sloboda 2001).

40 A critical issue in the logic of statistical reasoning is what constitutes support for a hypothesis. A vast array of ratios and likelihoods is required (Hacking 1964). Bayes' theorem is one formal tool to scrutinize how frequency information is related to probability judgments (Gigerenzer 2000; Clark 2015) in attempting to link relative frequencies and sample size. Bayes' theorem penalizes, amongst other things, unnecessary model parameters and thus encourages simplicity and may underlie musical sensibility (Temperley 2007).

41 Keeping track of events, foraging for predictive coherence is expanded by the scaffolding of the age of information and the cognitive revolution. This expansion is clearly emboldened by the same cataloging and quantification of pockets of information that underlie musical competence and composition. While expectations 
linked to probability judgments are only part of the story for musical aesthetic appreciation, they still seem to be elements of the feel for phenomena, which requires a number of information processing systems (Repp 2005).

\section{Abduction and Musical Expectations}

42 We arrive at some ideas rather quirkily, a fact that Peirce linked to abduction (genesis of an idea, musical or otherwise) and instinctive responses, rapid and heuristic (Peirce 1898). There is an experimental sensibility that pervades the creation of music (Gjerdingen 1999; Clarke 2008), that is a constant across cultures and throughout the world.

Abduction (genesis of an idea) is always constrained by context and ecology, as is musical composition and creativity; problem solving in context pervades musical expression. The creation of a new score and moments of foraging for coherent expression with others in a musical moment is constrained by cognitive capacity, individual competence, and that moment of pulling things together in the creation of something new amidst the resources available.

Music is rich in abduction. As the musicologist Eric Clarke discusses in describing Jimi Hendrix's performance of the "The Star-Spangled Banner," recorded at Woodstock in 1969 , there are different attributes of the perceived meaning of music. Sound, structure and ideology coexist and are simultaneously available in understanding Hendrix's rendition and the infusion of Blues, Rock and civil strife in the 1960's, and for the abductive expression of creative expansion from the familiar to less familiar as our horizons expanded. In the same way, numbers exist in the context of contact. Math, like art, underlies all forms of human expression (Lakoff \& Nunez 2000).

Good enough heuristics designed to predict predators, prey, food sources, and sexual success might have become linked to aesthetics (Dewey 1934; Meyer 1956, 1967). Prediction for one set of circumstances extends to new domains in our evolutionary ascent; our cognitive apparatus extends and expands and now can underlie aesthetic judgments because they reflect a response to violations of expectations (e.g., Hohwy 2013; Schulkin 2004).

In the context of music, the melodic structure is tied to implications or expectations and their realization (Narmour 1990). While the experience may not reflect the expectation, the way of explaining the behaviors and understanding the mechanisms do. Acknowledging Meyer, musicologists have long noted the inherent gestalt-like properties of music. Violations of expectations are one reliable feature linked to emotions, and while Meyer had doubts about the accuracy of the emotions in music, physical embodiment is embedded in these expectations and their violation in musical appreciation.

47 One feature inherent in some forms of music is tension (Meyer 1956; Dewey 1896), a conflict about expectations inherent in the psychophysics as it turns in harmonic combinations. Sloboda (1991) depicted a set of common emotional responses to music. The emotional responses are quite varied in response, not surprisingly, and they capture a wide range of human emotions (Juslin \& Sloboda 2001; see also Zentner 2011). In more detailed studies, the greater the deviation from expectations about the music's harmonic characteristics, the greater the emotional response (Steinbeis, Koelsch \& 
Sloboda 2006; Bianco et al. 2016). That is, we come prepared to recognize harmonic relationships, syntactically organized in the diverse semantic meanings expressed in music; deviations result in greater and more diverse cephalic responses (Meyer 1956, 1973).

The attention here becomes focused when encountering something that stands out as discrepant. Our curiosity is piqued; beholding an aesthetically pleasing or offensive object, our interest is aroused, our sensibility offended (Hebb 1949). Expectancy in information processing in the brain permeates and results in the serial organization of behavior "the serial order of behavior" (Lashley 1951).

John Dewey (1934) also held this view of preparedness, and is closely associated with theories in which behavior toward aesthetic objects reveals both appetitive and consummatory experiences in which stability is sought while precariousness is restrained. All of us, in the search for stable and secure relationships, experience both the appetitive or the search mode and the consummatory outcome (see Craig 1918).

51 The orientation of an expert, to be sure, is to the syntax or the form of music (Lerdhal 1992). Several studies have contrasted the fact that non-syntactical experiences of music tend to be devalued by musical experts; on the other hand, high experts tend to enjoy the atypical in musical composition (Smith 1987; Smith \& Witt 1989). Even novices, though, are sensitive to syntactic atypicality (Smith \& Melara 1990).

The search for something new, original, some form of discrepancy, evokes the cognitive pleasure that permeates expectations. A trade-off between what is familiar and what is novel pervades much of human and, no doubt, animal experience (Rozin 1976). Exposure tends to evoke enhanced preference for that to which one has been exposed, or with which one is already familiar (e.g., "oldies" music, comfort food, or a known and loved person).

Music is inherently familiar to us, even if it contains some unpredictable elements. This could play a role in why it is pleasurable to us. It is like eating variations of your mom's chicken soup... maybe a bit surprising, but always comforting and delightful. But this is only part of musical experience.

We derive pleasure from music for many reasons; "pleasure in the plural" as David Huron has noted. The pleasure we derive from music includes a capacity to prepare our mind to hear sound, amidst conceptual/auditory coherence, endless beauty in audition, and deep social symbolic meanings. We come prepared with biological pre-potent cephalic structures to the allure of the auditory, to the musical, to song and sound rich in meaning, with an allure to complete and fulfill expectations and experience pleasure (Huron 2008; Vuust \& Kringelbach 2010). As Huron notes, "[1]ike the Pacific bullfrog, experienced listeners of Western music rely on patterns that are serviceable, but not exactly right" (Huron 2008: 94).

\section{Musical Structure and Brain Activation}

Many neural systems are responsive to change or disruption and promote behavioral adjustments and activation. Underlying the detection are appraisal systems of diverse forms of expectancy (Schulkin 2013). Regions of the brain that may underlie musical syntax, probability judgments, and responses to novelty also underlie aesthetic experiences (Falk 2000). There is no extra area of the brain that evolved exclusively for 
aesthetic judgment. Thus, for instance, Broca's area is known for its involvement in the processing of the formal aspects of language but it is also involved in the syntax that underlies music. There are formal cognitive elements in musical structure (Maess et al. 2001; Patel et al. 1998; Lerdahl \& Jackendof 1999); syntactical hierarchical structure dominates both language and music (Patel 2003; Maess et al. 2001).

Rhythmic sensibility is inherent in language (Patel 2005), while melody is codified syntactically in music. Indeed, while language and music are not the same, they share similar neural origins (e.g. Broca's region; Patel 2003; Maess et al. 2001). This is evidenced by the fact that children with defects in language often show similar problems in musical syntactical competence. Syntactical relationships underlie both language and music (Cook 1998; Patel 2003).

Interestingly, a variety of brain imaging studies have linked the activation of Broca's area, in addition to other regions including the ventral premotor cortex, to musical syntax (Koelsch et al. 2002; Koelsch 2006; Maess et al. 2001).

Premotor and motor regions of the cortex, as well as basal ganglia, are activated in response to music, a phenomenon perhaps more enhanced in experienced musicians with specific expectations (e.g. Grahn \& Rowe 2009; Koelsch 2006). Some of the regions relevant to syntactical processing (Koelsch 2006) are active when a person is listening to rhythms (Brown 2007), or in contexts when managing expectations (Friston 2010; Koelsch, Vuust \& Friston 2018). Indeed, we know that unexpected or discrepant musical syntactical structure elicited greater activation of Broca's area (and the homologous right side) than a musical composition that was reported as syntactically predictable (Maess et al. 2001).

This sense of discrepancy holds for both rhythmic and tonal discrepancies, in addition to semantic discrepancies (Koelsch, Vuust \& Friston 2018; Smith \& Melara 1990). In other related studies, syntactical discrepancy has been linked to event or activationrelated brain potentials for both music and language recognition (Patel et al. 1998; Patel 2003). The neural mechanisms for the organization of musical judgment are not identical to those of human language expression, but there are interesting overlaps, one of which appears to be the activation of Broca's area (Koelsch et al. 2002; Koelsch et al. 2003). And it is regions like Broca's area that are essential for inherent neural order, syntax and the organization of action and perception.

Moreover, and importantly, motor imagery is replete with cognitive structure and is reflected in the activation of neural circuitry (Rizzolati \& Arbib 1998), and so auditory imagery is reflected in different regions of the brain, including anticipatory musical imagery (Rauschauser \& Scott 2009). Both hearing sounds or imagining them recruit many of the same brain regions (Zatorre 2001). Across a number of perceptual experiences, imagining entails the neural systems involved in seeing them, hearing them, or touching them. Imagine a visual rotation for example, versus actually looking at a rotating object; the time period needed to do so will actually reflect the size of the object (Shepard \& Cooper 1982). Very similar neural circuits are also activated when the object is imagined or viewed (Farah 1984; Kosslyn 1994).

61 Imagining music recruits auditory circuitry (Zatorre 2001). In other words, the neural structures that are active in imagining objects appear similar to those structures that are active when hearing or seeing them music (e.g. Kosslyn 1986, 1994). Put differently, 
hearing music, imagining music activates many of the regions linked to auditory perception and to music (Zatorre, Belin \& Penhume 2002; Zatorre \& Halpern 2005).

Perhaps one is now in a better position to understand the genius of Beethoven; deaf for years, he must have heard music imaginatively to compose the way he did. Think of the cognitive complexity, the richness of the later parts of Beethoven's life. In fact, we now know that musical hallucinations are often a feature of acquired deafness such as Beethoven's (Zatorre 2001; Zatorre Belin \& Penhume 2002). And we know that compensatory responses occur in auditory regions to compensate for visual loss (Rauschecker \& Scott 2009).

\section{Evolution, Music and Social Contact}

Music cuts across diverse cephalic capabilities and resources, including number, language and space. In the same way, music intersects with cultural boundaries, facilitating our "social self" (Mead 1934) by linking our shared experiences and intentions. Music and song are conduits for forging links across barriers, for making contact with others, and for being indoctrinated with the social milieu. There is little doubt that the fundamental link that music provides for us is about emotion and communicative expression in which the prediction of events is tied to diverse appraisal systems expressed in music (Meyer 1956; Sloboda 1985/2000; Huron 2008).

Music permeates the way in which we coordinate with one another in rhythmic patterns, reflecting self-generative cephalic expression tied to a rich sense of diverse musical semiotics (Meyer 1956; Cross \& Morley 2008; Schulkin 2000). Our repertoire of expression has incurred a crucial advantage: the ability to reach others and to communicate affectively laden messages.

A common theme noted by many inquirers is the social synchrony of musical sensibility (Brown 2007; Mithen 2009; Dreon 2013). This draws us together and, as a social species, remains essential to us; a chorus of expression in being with others, that fundamental feature of our life and of our evolutionary ascent. We marvel at the union of social adaptive bounds through communicative of a wide varies of species in nature (e.g. whales, bird song). Such bodily sensibility or expression is the delight that many species seem to express by exercising great form, great leaps out of the water, wonderful acoustical expressions.

Suzzane Langer highlighted the naturalism of the arts and the intensity of feeling (Langer 1953) - namely cognitively rich feelings expanding in symbolic breath and reflective of the cultures in which we live. Music is expressed across all cultures and has been with us, evolving for as long as we as a species have been here with instruments. Their complexity is a feature of the larger cultural milieu (Morley 2013). The evolutionary record suggests that musical instruments were perhaps well expressed over fifty thousand years ago in simple flutes and pipes (Morley 2013), and were depicted in our art (e.g., on bison horn). What began as an extension of communication in a social context became something greater, that was enjoyed for itself (Dewey 1934). Our evolution is tightly bound to music, and to the body as an instrument of exploration and discovery.

Music and language enhance each other with regard to cephalic function and behavioral adaptation, jointly expanding our capabilities. But then, language digs into 
everything, eventually, and is quite pervasive. Like language, music is essentially rooted in social contact. Both provide a vehicle for the child, for instance to gain a foothold in the world around her and to gain familiarity with objects that matter or those that are dangerous.

\section{Conclusion: Musical Delight}

Aesthetic appreciation, in its myriad forms, is an essential part of the human condition and is inextricably linked to a sense of well-being. Aesthetic experiences pervade human life (Johnson \& Schulkin 2020). Pragmatism demythologizes aesthetics. Dewey $(1925,1934)$ made that clear. Aesthetic sensibility underlies the rituals involving music and dance. The rain dance, drums and flutes, and the movement and stories of the earliest human aesthetic expression are all linked on a trajectory with our modern Broadway musicals, dinner theater, concerts, symphonies and ecclesiastical rituals across the human condition.

We come prepared to recognize the probabilities of musical events, or what Huron, echoing Meyer, has called his important book "sweet anticipation" (Huron 2008). Expectation in music are fundamental to our understanding of it. As Meyer put it, "expectation then is a product of the habit responses developed in connection with particular musical styles and of the modes of human perception, cognition and response - the psychological laws of mental life" (Meyer 1967: 30).

Dewey (1925) emphasized human growth within a behavioral context of diverse forms of appetitive and consummatory experiences that underlie all human activity, for which, as Meyer stated, "both music and life are experienced as dynamic processes of growth and decay, activity and rest and tension and release" (Meyer 1967: 261).

This view is at the heart of the pragmatist notion of human development and inquiry, musical and otherwise (Dewey 1934). Oliver Sacks, title for his book "Musicophilia" (2007) captures a fundamental feature of music, life affirming, endlessly valuable to our species.

\section{BIBLIOGRAPHY}

BACHORIK Justin Pierre, BANGERT Marc, LOUI Psyche, LARKE Kevin, BERGER Jeff, ROWE Robert \& Gottfried SCHLAUG, (2009), "Emotion in motion: Investigating the time-course of emotional judgements of musical stimuli," Music Perception, 26 (4), 355-64.

BERLYNE Daniel E., (1970), “Novelty, complexity, and hedonic value," Perception \& Psychophysics, 8, 279-86.

BERRIDGE Kent C., (2004), "Motivation concepts in behavioral neuroscience," Physiology and Behavior, 81, 179-209.

BERTHOZ Alain, (2002), The Brain's Sense of Movement, Cambridge, Mass., Harvard University Press. 
BIANCO Roberta, NOVEMBRE Giacomo, KELLER E. Peter \& Seung-Goo KIM, (2016), "Neural networks for harmonic structure in music perception and action," Neuroimage, 142, 1-15.

BROWN Steven, (2007), "Contagious heterophony: A new theory about the origins of music," Musicae Sceientiae, XI, 3-26.

CLARK Andy, (1998), Being There: Bringing Brain, Body and World Together, Cambridge, Bradford Books.

CLARK Andy, (2015), Surfing Uncertainty, Oxford, Oxford University Press.

CLARKE Eric F., (2008), Ways of Listening: An Ecological Approach to Perception of Musical Meaning, Oxford, Oxford University Press.

CLARKE Eric F. \& Nicholas COOK, (2004), Empirical Musicology, Oxford, Oxford University Press. ColombetTi Giovanna, (2017), The Feeling Body, Cambridge, Mass., MIT Press.

CooK Nicholas, (1998), Music: A Very Short Introduction, Oxford, Oxford University Press.

CRAIG Wallace, (1918), “Appetites and aversions as constituents of instinct," Biological Bulletin, 34, 91-107.

CROSS Ian, (2009), "The evolutionary basis of meaning in music: Some neurological and neuroscientific implications," in F. Clifford Rose (ed.), The Neurology of Music, London, Imperial College Press.

CROSS Ian \& Iain MORLEY, (2008), "The Evolution of Music: Theories, Definitions and Nature of the Evidence," in Stephen Malloch \& Colwyn Trevarthen (eds), Communicative Musicality, Oxford, Oxford University Press.

CUDDY Lola L. \& Carole A. LUNNEY, (2005), “Expectancies generated by melodic intervals: Perceptual judgements of melodic continuity," Perception \& Psychophysics, 57, 451-62.

DAMASIO Antonio R., (1994), Descartes' Error: Emotion, Reason, and the Human Brain, New York, Grosset/Putnam.

DARWIN Charles, (1872/1998), The Expression of the Emotions in Man and Animals, Oxford, Oxford University Press.

DEWEY John, (1895), “The theory of emotion,” Physiological Review, 2, 13-22.

DEWEY John, (1896), “The reflex arc concept in psychology,” Physiological Review, 3, 357-70.

DEWEY John, (1910/1965), The Influence of Darwin on Philosophy, Bloomington, Indiana University Press.

DEWEY John, (1925/1982), Experience and Nature, La Salle, Il., Open Court.

DEWEY John, (1929/1960), The Quest for Certainty, New York, Capricorn Books.

DEWEY John, (1934/1958), Art as Experience, New York, Capricorn Books.

DEWEY John, (1939/1966), Theory of Valuation, Chicago, University of Chicago Press.

DONALD Merlin, (2001), A Mind So Rare: The Evolution of Human Consciousness, New York, Norton. DONALD Merlin, (2004), "Hominid enculturation and cognitive evolution," in J. M. Luraciello, J. A. Hudson, R. Fibush \& P. J. Baver (eds), The Development of the Mediated Mind, Mawash, N.J., Erlbaum Press.

DREON Roberta, (2013), "What is evolutionary aesthetics for?," Aisthesis, 6, 95-111. 
DUNBAR Robin, (2016), Human Evolution, Oxford, Oxford University Press.

ENGEL Andreas K., FRISTON Karl J. \& Danica KRAGIC (eds), (2015), The Pragmatic Turn, Cambridge, Mass., MIT Press.

FALK Dean, (2000), "Hominid brain evolution and the origins of music," in N. L. Wallin, B. Merker \& S. Brown (eds), The Origins of Music, Cambridge, Mass., MIT Press.

FARAH Martha J., (1984), “The neurobiological basis of visual imagery: a componential analysis,"

Cognition, 18, 245-72.

FRISTON Karl, (2010), “The free energy principle: a unified brain theory?,” Nature Reviews, 11, 127-36.

GALLAGHER Shaun, (2005), How the Body Shapes the Mind, Oxford, Oxford University Press.

GALLAGHER Shaun, (2020), Action and Interaction, Oxford, Oxford University Press.

GALLESE Vittorio, FADIGA Luciano, FOGASSI Leonardo \& Giacomo RIZzolATTI, (1996), “Action recognition in the premotor cortex," Brain, 119, 593-609.

GIBSON James J., (1979), The Ecological Approach to Visual Perception, Boston, Houghton-Mifflin. GIGERENZER Gerd, (2000), Adaptive Thinking, Oxford, Oxford University Press.

GJERDINGEN Robert O., (1990), “Categorization of musical patterns by self-organizing neuronlike networks," Music Perception, 8, 339-70.

GJERDINGEN Robert O., (1999), “An experimental music theory?,” in N. Cook \& M. Everist (eds), Rethinking Music, Oxford, Oxford University Press.

GJERDINGEN Robert O., (2007), "The psychology of music," in T. Christensen (ed.), The Cambridge History of Western Music Theory, Cambridge, Cambridge University Press, 960-81.

GOODMAN Nelson, (1955/1978), Fact, Fiction and Forecast, New York, Bobbs-Merill Co.

GRAHN Jessica Adrienne \& James B. ROWE, (2009), "Feeling the beat: Premotor and striatal interacions in musicians and non-musicians during beat perception," Journal of Neuroscience, 29, 7540-8.

HACKING Ian, (1964), Logic of Statistical Inference, Cambridge, Cambridge University Press.

HACKING Ian, (1999), The Taming of Chance, Cambridge, Cambridge University Press.

HATTEN Robert S., (2004), Interpreting Musical Gesture, Bloomington, Indiana University Press.

HEBB Donald O., (1949), The Organization of Behavior, New York, Wiley.

HELMHOLTZ Hermann von, (1873), Popular Lectures in Scientific Subjects, translated by E. Atkinson with introduction by J. Tyndale, London, Longmans Green.

ноншу Jakob, (2013), The Predictive Mind, Oxford, Oxford University Press.

HURON David, (2008), Sweet Anticipation: Music and the Psychology of Expectation, Cambridge, Mass., MIT Press.

JEANNEROD Marc, (1997), The Cognitive Neuroscience of Action, Oxford, Blackwell. JOHNSON Mark L., (1993), Moral Imagination, Chicago, University of Chicago Press. JOHNSON Mark L., (2007), The Meaning of the Body, Chicago, University of Chicago Press. 
JOHNSON Mark L. \& Steve LARSON, (2003), "'Something in the Way She Moves'- Metaphors of Musical Motion," Metaphor \& Symbol, 18, 63-84.

JOHNSON Mark L. \& Jay SCHULKIN, (2020), "Common Currency of our aesthetic sensibility," Transactions of the C. S. Peirce Society, 56, 326-48.

JUSLIN Patrick N. \& John A. SLOBODA, (2001), Music and Emotion, Oxford, Oxford University Press. KOELSCH Stefan, (2006), "Significance of Broca's area and ventral premotor cortex for musicsyntactic processing," Cortex, 42, 518-20.

KOELSCH Stefan, GUNTER Thomas C., CRAMON D. Y. von \& Stefan ZYSSET, (2002), "Bach speaks: A cortical 'language-network' serves the processing of music,” NeuroImage, 17, 956-66.

KOELSCH Stefan, GUNTER Thomas C., SCHRÖGER Erich \& Angela D. FRIEDERICI, (2003), "Processing tonal modulations: An ERP study," Journal of Cognitive Neuroscience, 15, 1149-59.

KOELSCH Stefan, vUUST Peter \& Karl FRISTON, (2018), "Predictive processes and the peculiar case of music," Trends in Cognitive Science, 23 (1), 63-77.

KossLYN Stephen M., (1986), Image and Mind, Cambridge, Mass., Harvard University Press.

KOSSLYN Stephen M., (1994), Image and Brain, Cambridge, Mass., MIT Press.

KRUMHANSL Carol L., (2002), "Music: A link between cognition and emotion," Current Directions in Psychological Science, 11, 45-50.

KRUSE Felicia E., (2005), “Musical meaning: A Peircean solution to Langer's dualism,” Transactions of the Charles Sanders Peirce Society, 41, 762-78.

KRUSE Felicia E., (2011), “Temporality in musical meaning: A Peircean/Deweyan semiotic approach," The Pluralist, 6, 50-63.

LAKOFF George \& Mark JOHnson, (1999), Philosophy in the Flesh: the Embodied Mind and its Challenge to Western Thought, New York, Basic Books.

LAKOFF George \& Rafael E. NUNEZ, (2001), Where Mathematics Comes From, New York, Basic Books.

LANGER Susanne K., (1953), Feeling and Form, New York, Scribner.

LASHLEY Karl S., (1951), "The problem of serial order in behavior," in L. A. Jeffres (ed.), Cerebral Mechanisms in Behavior, New York, Wiley, 110-33.

LERDAHL Fred \& Ray S. JACKENDOFF, (1983), A Generative Theory of Tonal Music, Cambridge, Mass., MIT Press.

LERDAHL Fred, (1992), "Cognitive constraints on compositional systems," Contemporary Music Review, 6, 97-121.

LOEWENSTEIN George, (1996) “The psychology of curiosity,” Psychological Bulletin, 116, 75-98.

MAESS Burkhard, KOELSCH Stefan, GUNTER Thomas C. \& Angela D. FRIEDERICI, (2001), "Musical syntax is processed in Broca's area: an MEG study," Nature Neuroscience, 4, 540-5.

MEAD George Herbert, (1934), Mind, Self, and Society, Chicago, University of Chicago Press. MERLEAU-PONTY Maurice, (1962), The Phenomenology of Perception, New York, Routledge and Kegan Paul.

MEULDER Michel, (2010), Helmholtz: From Enlightenment to Neuroscience, Cambridge, Mass., MIT Press. MEYER Leonard B., (1956), Emotion and Meaning in Music, Chicago, University of Chicago Press. 
MEYER Leonard B., (1967), Music, the Arts and Ideas, Chicago, University of Chicago Press.

MEYER Leonard B., (2000), The Spheres of Music: A Gathering of Essays, Chicago, University of Chicago Press.

Miell Dorothy, MACDONALD Raymond \& David J. HARGREAVES (eds), (2005), Musical Communication, Oxford, Oxford University Press.

MITHEN Steven, (2009), “The music instinct,” NY Academy of Sciences, 1169, 3-12.

MORGAN Emily, FOGEL Allison, NAIR Anjali \& Aniruddh D. PATEL, (2019), "Statistical learning and gestalt like principles predict melodic expectations," Cognition, 189, 23-34.

MORLEY Iain, (2013), The Prehistory of Music. Human Evolution, Archaeology, and the Origins of Musicality, Oxford, Oxford University Press.

NARMOUR Eugene, (1990), The Analysis and Cognition of Basic Melodic Structures, Chicago, University of Chicago Press.

NARMOUR Eugene, (2008), “My intellectual father," Music Perception, 25, 485-7.

PATEL Aniruddh D., (2003), “Language, music, syntax and the brain,” Nature Neuroscience, 6, 674-81.

PATEL Aniruddh D., (2005), "The relationship of music to the melody of speech and to syntactic processing disorders in aphasia," Annals of the New York Academy of Sciences, 1060, 59-70.

PATEl Aniruddh D., GIBSON Edward, RATNER Jennifer, BESSON Mireille \& Phillip J. HOLCOMB, (1998), "Processing syntactic relations in language and music: An event-related potential study," Journal of Cognitive Neuroscience, 10, 717-33

PEIRCE Charles Sanders, (1868), “Questions concerning certain faculties claimed for man,” Journal of Speculative Philosophy, 2, 103-14.

PEIRCE Charles Sanders, (1878), "Deduction, Induction and Hypothesis," Popular Science Monthly, 13, $470-82$.

PEIRCE Charles Sanders, (1898/1992), Reasoning and the Logic of Things, Cambridge, Mass., Harvard University Press.

RAUSCHAUSER Josef P. \& Sophie K. SCOTT, (2009), "Maps and streams in the auditory cortex: nonhuman primates illuminate human speech processing," Nature Neuroscience, 12 (6), 718-24. READER Simon M. \& Kevin N. LALAND, (2002), "Social intelligence, innovation, and enhanced brain size in primates," PNAS, 99, 4436-41.

REPP Bruno H., (2005), "Sensorimotor synchronization: A review of the tapping literature," Psychonomic Bulletin and Review, 12, 969-92.

RIZzolATI Giacomo \& Michael A. ARBIB, (1998), "Language within our grasp," Trends in Neuroscience, 21, 188-94.

ROZIN Paul, (1976), "The evolution of intelligence and access to the cognitive unconscious," in J. Sprague \& A. N. Epstein (eds), Progress in Psychobiology and Physiological Psychology, New York, Academic Press.

ROZIN Paul, (1998), "Evolution and development of brains and cultures," in M. S. Gazzaniga \& J. S. Altman (eds), Brain and Mind: Evolutionary Perspectives, Human Frontiers Sciences Program, Strasbourg, France. 
RozIN Paul \& Alexander RozIN, (2006), "Documenting and explaining the common AAB pattern in music and humor: Establishing and breaking expectations," Emotion, 6, 349-55.

RUSSo Franck A. \& Lola L. CUDDY, (1999), "Motor theory of melodic expectancy," in Acoustical Society of America ASA/EAA/DAGA 1999 meeting lay language papers, Berlin.

SACKS Oliver, (2008), Musicophilia, New York, Vintage Press.

SCHULKIN Jay, (2000), Roots of Social Sensibility and Neural Function, Cambridge, Mass., MIT Press. schULKIN Jay, (2004), Bodily Sensibility: Intelligent Action, Oxford, Oxford University Press. sCHULKIN Jay, (2009), Cognitive Adaptation: A Pragmatist Perspective, Cambridge, Cambridge University Press.

schUlKIN Jay, (2011), Adaptation and Well Being, Cambridge, Cambridge University Press.

SCHULKIN Jay, (2013), Reflections on the Musical Mind, Princeton, Princeton University Press.

SHEPARD Robert N. \& Lynn A. COOPER, (1982), Mental Images and Their Transformations, Cambridge, Mass., MIT Press.

SLOBODA John A., (1985/2000), The Musical Mind, Oxford, Oxford University Press.

SLOBODA John A., (1991), “Music structure and emotional response: Some empirical findings,"

Psychology of Music, 19, 110-20.

SLOBODA John A., (2008), “Embracing Uncertainty,” Music Perception: An Interdisciplinary Journal, 25, 489-91.

SMITH David J., (1987), "Conflicting aesthetic ideals in a musical culture," Music Perception, 4, 373-92.

SMITH David J. \& Robert J. MELARA, (1990), “Aesthetic preference and syntactic prototypicality in music: 'Tis the gift to be simple," Cognition, 34, 279-98

SMITH David J. \& Jordan N. WITT, (1989), “Spun steel and stardust: The rejection of contemporary compositions," Music Perception, 7, 169-86.

STEINBEIS Nikolaus, KOELSCH Stefan \& John A. SLOBODA, (2006), “The role of harmonic expectancy violations in musical emotions: Evidence from subjective, physiological, and neural responses," Journal of Cognitive Neuroscience, 18, 1380-93.

STERLING Peter \& Simon LAUGhlin, (2017), Principles of Neural Design, Cambridge, Mass., MIT Press. TALLIS Raymond, (2010), Michelangelo's Finger: An Exploration of Everyday Life, New Haven, Yale University Press.

TARR Bronwyn, LAUNAY Jacques \& Robin I. M. DUNBAR, (2014), "Music and social bonding," Frontiers in Psychology, 5, 1-5.

TEMPERLEY David, (2007), Music and Probability, Cambridge, Mass., MIT Press.

THOMPSON William Forde, CUDDY Lola L. \& Cheryl PLAUS, (1997), “Expectancies generated by melodic intervals: Evaluation of principles of melodic implication in a melody-completion task," Perception and Pscyhophysics, 59, 1060-76.

TOMASELlo Michael, (2009), Why We Cooperate, Cambridge, Mass., MIT Press.

TOMASELLO Michael \& Malinda CARPENTER, (2007), "Shared intentionality," Developmental Science, 12, $121-5$ 
VARELA Francisco J., ROSCH Eleanor \& Evan THOMPSON, (1991), The Embodied Mind, Cognitive Science and Human Experience Series, Cambridge, Mass., MIT Press.

VUUST Peter \& Morten L. KRINGELBACH, (2010), "The pleasure of music," in M. L. Kringelbach \& K. C. Berridge (eds), Pleasures of the Brain, Oxford, Oxford University Press.

VUUST Peter, OSTERGAARD Leif, PALLESEN Karen Johanne \& Christopher J. BAILEy, (2009), "Predictive coding of music-brain responses to rhythmic incongruity," Cortex, 45, 80-92.

Williams Daniel, (2018), "Pragmatism and the predictive mind," Phenon. and Cog. Neuro., 17, 835-59. ZATORRE Robert J., (2001), "Neural specializations for tonal processing," Annals of the New York Academy of Sciences, 930, 193-210.

ZATORRE Robert J., BELIN Pascal \& Virginia B. PENHUME, (2002), "Structure and function of auditory cortex: music and speech," Trends in Cognitive Sciences, 6 (1), 37-46.

ZATORRE Robert J. \& Andrea R. HALPERN, (2005), "Mental concerts: Musical imagery and auditory cortex," Neuron, 47, 9-12.

ZBIKowSKI Lawrence M., (2005), Conceptualizing Music, Oxford, Oxford University Press.

ZENTNER Marcel, (2011), "Homeric prophecy: An essay on music's primary emotions," Music Analysis, 29, 102-25.

\section{ABSTRACTS}

Pragmatists views, like those of John Dewey's about music, emphasize the social nature of musical sensibility, instrumental expressions and adaptation to changing circumstances. Indeed, expectancy and violations of those expectations in music are tied to memory and human development. Cephalic (mind/brain/body) factors that underlie what we expect, and variation on the expected, inhere in musical experiences. Music is a piece of nature and is tied to movement and dance and rooted in social contact. Music of course serves many functions in our lives. From the first sounds to some of the last, human well-being and music are ripe across the life cycle of human experience.

\section{AUTHOR}

JAY SCHULKIN

Georgetown University

jjs54[at]georgetown.edu 